\title{
Técnicas normativas y aplicativas en las medidas laborales ante el COVID 19 en España( $\left.\left.{ }^{*}\right)^{* *}\right)$
}

\section{Legislative and application techniques in labour measures at COVID 19 in Spain}

\author{
Jesús Cruz Villalón ${ }^{(* *)}$ \\ Universidad de Sevilla (Sevilla, España)
}

\begin{abstract}
Resumen: La declaración del estado de alarma por el Gobierno español en marzo de 2020, que ha confinado a la población en sus domicilios, con efectos muy intensos de paralización de la actividad empresarial, ha tenido un impacto muy notable en el ámbito de lo laboral, con medidas muy relevantes, de fuerte impacto tanto sobre el mercado de trabajo como sobre la legislación laboral. Entre las medidas más destacadas señalaríamos las siguientes: (1) reglas de preferencia del trabajo a distancia para aquellas empresas que se vieran obligadas a cerrar los centros de trabajo y en la medida de lo posible se evitara la destrucción de esos empleos; (2) establecimiento de un sistema de suspensión de los contratos de trabajo por fuerza mayor, favorable tanto para las empresas como para los trabajadores, que igualmente evitase la adopción de despidos masivos; (3) declaración del carácter injustificado de los despidos que pretendiesen motivarse por la paralización de la actividad productiva derivada de la crisis sanitaria; (4) fórmulas favorecedoras de la conciliación de las responsabilidades familiares y laborales durante el desarrollo de las medidas frente a la pandemia; (5) fórmula excepcional de permiso retribuido recuperable; (6) medidas económicas de atención a los trabajadores sin actividad laboral a través de prestaciones de Seguridad Social; (7) introducción de una prestación nueva de Seguridad Social como Ingreso Mínimo Vital.
\end{abstract}

El presente estudio, dejando de lado el análisis en detalle del contenido de las medidas adoptadas, pretende analizar el proceso de elaboración de estas normas de urgencia, la intervención de los diversos poderes públicos tanto en el proceso de aprobación como de aplicación, así como el protagonismo de la concertación social, la negociación colectiva y la participación de los trabajadores en la empresa. Desde este enfoque, se afrontan las especialidades de las medidas desde la perspectiva del juego de las reglas relativas a Fuentes del Derecho, así como del papel desempeñado por los actores protagonistas habituales en el desarrollo de nuestro sistema de relaciones laborales.

Palabras claves: Técnica normativa laboral - Legislación de urgencia - Concertación social - Facultades administrativas laborales

Abstract: The declaration of the state of alarm by the Spanish Government in March 2020 , which has confined the population to their homes, with very intense effects of paralyzing business activity, has had a very notable impact in the field of work, with very

(*) Nota del Editor: este artículo fue recibido el 30 de abril de 2020 y su publicación fue aprobada el 14 de agosto de 2020.

(") Artículo actualizado hasta el 30 de julio de 2020.

${ }^{* * *}$ Catedrático de Derecho del Trabajo y de la Seguridad Social en la Universidad de Sevilla, España. Director del Departamento de Derecho del Trabajo y la Seguridad Social de la misma casa de estudios. ORCID: https://orcid.org/0000-0002-1275-5289?lang=en. Correo electrónico: jesuscruz@us.es 
relevant measures, with a strong impact on both the labour market and labour legislation. Among the most important measures are the following: (1) rules of preference for distance working for those companies that were forced to close their work centres and, as far as possible, avoid the destruction of these jobs; (2) establishment of a system of suspension of employment contracts due to force majeure, favourable to both companies and workers, which would also avoid the adoption of mass redundancies; (3) declaration of the unjustified nature of redundancies that were intended to be motivated by the cessation of productive activity due to the health crisis; (4) formulas favouring the conciliation of family and work responsibilities during the development of the measures against the pandemic; (5) exceptional formula of recoverable paid leave; (6) economic measures to attend to workers without work activity through Social Security benefits; (7) introduction of a new Social Security benefit as Minimum Life Income.

The present study, leaving aside the significance and scope of the measures adopted in this context, aims to analyze the process of elaboration of these emergency regulations, the intervention of the various public powers both in the process of approval and application, as well as the marginal role of social consensus, collective bargaining and the participation of workers in the company. In this way, the specialties of the measures are addressed from the perspective of the game of the rules related to Sources of Law, as well as the role played by the habitual protagonists in the development of our system of labour relations.

Keywords: Technical labor regulations - Emergency legislation Social agreement labor - Administrative powers

\section{Las medidas laborales y sociales como referente central: un análisis desde la técnica jurídica}

El fortísimo impacto de la pandemia en España ha exigido que la declaración del estado de alarma por el Gobierno ${ }^{(1)}$, a mediados de marzo de 2020, haya provocado medidas de enorme repercusión en la vida cotidiana del conjunto de la población. La imposición de un confinamiento en los domicilios particulares de la práctica totalidad de los residentes en todo el territorio español ha tenido un impacto sobre muy diversos aspectos de la vida cotidiana, entre los que destacan, a los efectos que nos interesa tener en cuenta en estos momentos, los que afectan a la suspensión de la actividad económica, lo que, por efecto derivado, ha desencadenado, automáticamente, una importante alteración o interrupción de multitud de trabajos. Como de manera plástica se ha descrito bien, la efectividad del confinamiento ha requerido que desde el poder público se produzca un modo de "coma inducido" de la actividad económica. Se trata de algo que, dentro de la ortodoxia de las políticas económicas, se presenta como una medida contra natura, dado que la práctica universal es que el poder público actúe a favor de la dinamización económica y de establecer mecanismos que promuevan el desarrollo económico al máximo nivel posible.

En todo caso, la profundidad del confinamiento ha tenido un efecto automático sobre el empleo, de modo que prácticamente todos los trabajadores ocupados se han visto afectados por las medidas de confinamiento. Unos porque han debido seguir prestando sus servicios en sus domicilios a distancia cambiando no sólo el lugar de realización de su trabajo, sino que, además, como efecto reflejo, han visto modificadas muchas de sus condiciones de trabajo; se calcula que en torno a tres millones de trabajadores han pasado a prestar servicios a distancia, lo que representa en torno al $16,2 \%$ de la población ocupada, cuando previamente en 2019 el trabajo a distancia sólo representaba el $4,8 \%$. Otros porque se ha paralizado por completo la actividad productiva de sus empresas, lo que les ha dejado sin trabajo, por mucho que se hayan establecido medidas laborales orientadas a favorecer que ello no produzca una destrucción de sus empleos sino exclusivamente un paréntesis temporal en tanto que dure la situación de excepcionalidad; las suspensiones de los contratos de trabajo ha superado los 3,4 millones de trabajadores, lo que viene a representar el $25 \%$ de los ocupados en el sector privado, al tiempo que se ha

(1) Real Decreto 463/2020, de 14 de marzo (BOE 14 de marzo), por el que se declara el estado de alarma para la gestión de la situación de crisis sanitaria ocasionada por el COVID-19, modificado por el RD 465/2020, de 17 de marzo (BOE 18 de marzo), estado de alarma prorrogado por el Real Decreto 476/2020, de 27 de marzo (BOE 28 de marzo), prorrogado por segunda vez por el Real Decreto 487/2020, de 10 de abril (BOE 11 de abril); prorrogado por tercera vez por el Real Decreto 492/2020, de 24 de abril (BOE 25 de abril); prorrogado por cuarta vez por el Real Decreto 514/2020, de 8 de mayo (BOE 9 de mayo 2020); prorrogado per la quinta veza por el Real Decreto 537/2020, de 22 de mayo (BOE 22 de mayo); y por sexta y última vez por el Real Decreto 463/2020, de 5 de junio (BOE 6 de junio), hasta el 20 de junio. 
destruido del orden de 1,35 millones de empleos. Finalmente, aquellos que han seguido trabajando en sus centros de trabajo, porque realizan tareas en servicios esenciales o en sectores críticos donde la trascendencia de su trabajo se ha visto exponencialmente incrementada, o bien porque se ha permitido un mínimo de actividad productiva en algunos sectores (construcción e industria), incluso éstas durante un pequeño lapso de tiempo también interrumpidas, pero que, en todo caso, han tenido que reforzar las medidas de prevención de riesgos laborales a efectos de evitar la propagación del contagio.

Todo ello ha exigido la adopción de medidas laborales de reacción, orientadas a priorizar el teletrabajo, a canalizar las paradas de la producción a través de suspensiones de los contratos de trabajo en las que el empleador no debe abonar su salario y ello viene compensado porque la Seguridad Social abona el $70 \%$ de la retribución dejada de percibir, intentando evitar los despidos, adoptar medidas reactivas frente a la fuerte destrucción del empleo temporal, atender las paradójicas carencias de empleo en la actividad agrícola, así como establecer reglas singulares para quienes siguen trabajando, especialmente en sectores críticos o especialmente sensibles ${ }^{(1)}$. Posteriormente, vendrían medidas orientadas a sostener la economía y, especialmente, a favorecer la reincorporación al trabajo de los trabajadores que tenían sus contratos suspendidos, especialmente a través de la flexibilidad en la recuperación del empleo y en reducciones en las cotizaciones empresariales a la Seguridad Social ${ }^{(3)}$.

Como complemento imprescindible a todo lo anterior, el número de personas que se han quedado sin trabajo, sea temporal o por tiempo indefinido, es muy elevado y, especialmente, ha supuesto una intensificación muy notable de situaciones de necesidad económica por pérdida de ingresos que incluso han afectado al acceso a bienes y servicios básicos ${ }^{(4)}$. Por tanto, desde el primer momento se detectó que las prestaciones económicas proporcionadas por nuestro sistema de Seguridad Social $y$, más ampliamente, de todo el entramado de nuestro modelo de protección social no llegaba a muchas de las situaciones de desamparo económico que se han producido $y$, por ello, la incorporación de nuevas de medidas de carácter social en este terreno ha sido importante y decisiva para compensar los perjuicios provocados por la paralización de la actividad económica. Las medidas en el ámbito de la Seguridad Social se han dirigido esencialmente a garantizar prestaciones económicas suficientes a quienes ha dejado de trabajar por suspensiones o despidos, así como por reducciones de jornadas. Todo ello se ha materializado en el dato de que, durante el período álgido del confinamiento, el sistema de Seguridad Social ha llegado a abonar prestaciones económicas a un total de 6,3 millones de personas. Como medida estructural de particular impacto de encuentra la introducción de una nueva prestación de Seguridad Social, denominada Ingreso Mínimo Vital, dirigida a atender a las situaciones de pobreza extrema, con particular impacto en quienes tradicionalmente quedan fuera del ámbito de protección de la Seguridad Social, por

(2) Real Decreto-Ley 6/2020, de 10 de marzo (BOE 11 de marzo), por el que se adoptan determinadas medidas urgentes en el ámbito económico y para la protección de la salud pública; Real Decreto-Ley 7/2020, de 12 de marzo (BOE 13 de marzo), por el que se adoptan medidas urgentes para responder al impacto económico del COVID-19; Real Decreto-Ley 8/2020, de 17 de marzo (BOE 18 de marzo), de medidas urgentes extraordinarias para hacer frente al impacto económico y social del COVID-19; Real DecretoLey 9/2020, de 27 de marzo (BOE 28 de marzo), por el que se adoptan medidas complementarias, en el ámbito laboral, para paliar los efectos derivados del COVID-19; Real Decreto-Ley 10/2020, de 29 de marzo, por el que se regula un permiso retribuido recuperable para las personas trabajadoras por cuenta ajena que no presten servicios esenciales, con el fin de reducir la movilidad de la población en el contexto de la lucha contra el COVID-19; Real Decreto-Ley 13/2020, de 7 de abril (BOE 8 de abril), por el que se adoptan determinadas medidas urgentes en materia de empleo agrario; Real Decreto-Ley 15/2020, de 21 de abril (BOE 22 abril), de medidas urgentes complementarias para apoyar la economía y el empleo; Real Decreto-Ley 16/2020, de 28 de abril (BOE 29 de abril), de medidas procesales y organizativas para hacer frente al COVID-19 en el ámbito de la Administración de Justicia. C. Alfonso Mellado y G. Fabregat Monfort, COVID-19: Medidas del RDL 8/2020 en el ámbito laboral. Doctrina, legislación y formularios, Ed. Tirant lo Blanch, Valencia 2020. C. H. Preciado Domènech, Aspectos laborales y de Seguridad Social del Real Decreto-Ley 8/2020, de 17 de marzo, de medidas urgentes extraordinarias para hacer frente al impacto económico y social del COVID-19. J. Mercader Uguina, Compromiso de empleo en los ERTES por fuerza mayor y COVID-19: más dudas, más incertidumbre, Foro de Labos. E. Rojo Torrecilla, Aula luslaboralista UAB. Dos meses que cambiaron las relaciones laborales. J. A. Fernández Avilés, Un repaso de síntesis a las modificaciones operadas en el DTSS desde el Real Decreto 463/2020 de declaración del estado de alarma. ¿Es suficiente este derecho laboral excepcional «por aluviones» frente a la pandemia del COVID-19?, CEF 445 (2020).

(3) Real Decreto-Ley 18/2020, de 12 de mayo (BOE 13 de mayo), de medidas sociales en defensa del empleo; Real Decreto-Ley.

(4) Además de las normas mencionadas en la nota precedente, véase. Real Decreto-Ley 11/2020, de 31 de marzo (BOE 1 de abril), por el que se adoptan medidas urgentes complementarias en el ámbito social y económico para hacer frente al COVID-19. 
encontrarse en la economía informal o fuera por completo del mercado de trabajo(5)

En definitiva, la actuación en el campo de lo laboral y de la Seguridad Social ha constituido uno de los pilares básicos de la actuación del Gobierno para contrarrestar los efectos de la paralización económica, a su vez impuesta como necesaria a resultas de la obligada limitación de la movilidad de los ciudadanos en el marco del estado de alarma. Dicho de otro modo, las medidas laborales y sociales no han constituido un mero elemento de acompañamiento a la actuación para hacer frente a la crisis sanitaria, sino que han conformado un referente básico dentro del conjunto de las medidas adoptadas en este complejo escenario.

En todo caso, no pretende ser el objetivo inmediato de este trabajo el análisis del contenido de las medidas laborales y sociales que se han adoptado desde la perspectiva material, su alcance e impacto. Dejando al margen la importancia de la anterior perspectiva, a la que hemos dedicado su atención a través de otros textos ${ }^{(6)}$, en esta ocasión nuestra pretensión es de enfoque más general en el plano de lo técnico jurídico y del juego de las Fuentes del Derecho en nuestro ordenamiento jurídico aplicadas a un contexto difícilmente previsible, pero para el que se presupone que nuestro sistema debe tener instrumentos jurídicos con los que actuar.

El punto de partida a estos efectos, es que la declaración del estado de alarma no constituye, ni mucho menos, una excepcionalidad en la aplicación de nuestro sistema normativo y, mucho menos, en las previsiones constitucionales contempladas al efecto. En concreto, el estado de alarma no puede constituir un fundamento para alterar nuestro sistema normativo y, en particular, nuestro sistema de Fuentes del Derecho.

Eso sí, el propio ordenamiento jurídico contempla vías singulares de actuación frente a situaciones de cierta excepcionalidad y la derivada de la crisis sanitaria es emblemática a estos efectos. De este modo, sin haberse alterado las bases conforme a las que se construye nuestra legislación laboral y de protección social, las medidas adoptadas en este terreno, tanto en el ámbito normativo como en el ejecutivo o aplicativo, han presentado significativas especialidades, que merece la pena analizar. Esas especialidades no presentan un alcance menor, aunque sin llegar a alterar el diseño constitucional de nuestro sistema de relaciones laborales, ni siquiera el modelo práctico desarrollado a lo largo de todas estas décadas de funcionamiento democrático de las relaciones laborales. Eso sí, presentan una trascendencia que merece la pena analizar, a pesar de su impacto en principio limitado en el tiempo, dado que es la primera ocasión en la que se ha presentado un panorama de esta envergadura en la ya larga experiencia democrática de nuestro país, que ha requerido adoptar medidas excepcionales, que necesariamente van a dejar su poso. Incluso, lo extraordinario de la situación vivida, provoca que se acuñe la idea de que volveremos a una "nueva normalidad". Sin lugar a dudas, el impacto económico, social y cultural será indiscutible para el futuro, al punto que ello obliga a reflexionar hasta qué punto esa posible "nueva normalidad" puede incluso incidir en la perspectiva jurídica, para desembocar en una "nueva normalidad jurídica".

\section{La limitación de derechos fundamentales y de derechos constitucionales}

Por su trascendencia, el primer interrogante es el de hasta qué punto el estado de alarma ha limitado o impedido el ejercicio de derechos fundamentales 0 , más ampliamente, constitucionalizados desde la perspectiva laboral. Desde el punto de vista formal, lo que se contempla en la Ley Orgánica reguladora del estado de alarma es que éste podrá "limitar la circulación o permanencia de personas", aparte de poderse adoptar otras medidas que pueden afectar al derecho de propiedad, a la libertad de empresa o al acceso a servicios o productos $^{(7)}$ De este modo, se podría decir

(5) Real Decreto-Ley 20/2020, de 29 de mayo (BOE 1 de junio), por el que se establece el ingreso mínimo vital; Real Decreto-Ley 21/2020, de 9 de junio (BOE 10 de junio), de medidas urgentes de prevención, contención y coordinación para hacer frente a la crisis sanitaria ocasionada por el COVID-19; Real Decreto-Ley 24/2020, de 26 de junio (BOE 27 de junio), de medidas sociales de reactivación del empleo y protección del trabajo autónomo y de competitividad del sector industrial; Real Decreto-Ley 25/2020, de 3 de julio (BOE 6 de julio), de medidas urgentes para apoyar la reactivación económica y el empleo.

(6) Para mayor información, véase. Cruz Villalón, J. (2020). Teletrabajo y coronavirus: de la emergencia a la permanencia. Derecho de las Relaciones Laborales, 4, 406-418. Véase Cruz Villalón, J. (2020). El ERTE en la fase de retorno a la normalidad, Actum Social, 158, 48-54. Véase Cruz Villalón, J. (en prensa). Las medidas de evitación de la destrucción de empleo ante la emergencia sanitaria: incentivos al retorno del empleo y sanciones frente a la resolución contractual. Bomarzo.

(7) Artículo 11 Ley Orgánica 4/1981, de 1 de junio (BOE 5 de junio), de los estados de alarma, excepción y sitio. 
que la declaración del estado de alarma no puede afectar de manera directa al disfrute y ejercicio de ninguno de los derechos laborales reconocidos constitucionalmente, ni en su perspectiva individual ni en la colectiva.

A pesar de ello, la intensidad de la limitación de la libre circulación ha sido de tal grado que ha provocado un impacto reflejo inmediato sobre el derecho al trabajo y el deber de trabajar; lo primero, en la medida en que ha impedido la continuidad de multitud de trabajos, lo segundo, en cuanto que se han desarrollado en este contexto los deberes de ejecución de prestaciones personales obligatorias ${ }^{(8)}$ En paralelo ha limitado sustancialmente la libertad de empresa en el marco de la economía de mercado (artículo $38 \mathrm{CE}$ ), en la medida en que ha obligado al cierre de negocios. Más aún, el efecto reflejo es de tal magnitud que, aunque no limita otros derechos laborales, especialmente de carácter colectivo, los hace especialmente complicados en su ejercicio. Baste, sólo a título de ejemplo, tener presente cómo las imposiciones derivadas de la necesidad de mantener distancia de seguridad interpersonal dificulta el desarrollo de reuniones presenciales tanto sindicales como asamblea de trabajadores, lo sean a efectos de negociación colectiva, de actividad sindical, de desarrollo de los procesos de consultas en los procedimientos de suspensión de los contratos por causas económicas, técnicas, organizativas o productivas; sin olvidar tampoco cómo las actividades consideradas como críticas o esenciales durante el período de emergencia hace presumir que las mismas tienen igualmente el carácter de mínimos esenciales a efectos del posible desarrollo del derecho de huelga.

En todo caso, sin poder entrar en el análisis de los aspectos anteriores que, por muy importantes que puedan ser, se van a circunscribir en el ámbito temporal extraordinario del período correspondiente al estado de alarma. Más allá de lo anterior, me interesa llamar la atención acerca de los importantes desafíos que para el futuro y de posible alcance permanente puedan tener esa anunciada "nueva normalidad" tras la superación de la emergencia sanitaria. En este otro territorio de lo que puede surgir como un debate más en el medio y largo plazo, me parecen especialmente significativas ciertas medidas que se barruntan en orden a controlar futuros contagios o diseminación del virus, que pueden afectar al derecho a la privacidad de las personas y, en particular, de los trabajadores (artículo $18 \mathrm{CE}$ ). En este ámbito van a resurgir con fuerza los debates en torno a los controles de la vigilancia de la salud de los trabajadores, incluidos, por ejemplo, la extensión de controles cotidianos a la totalidad de la plantilla de la temperatura al ingreso en el centro de trabajo ${ }^{(9)}$ Esto último entraría dentro de la categoría de lo que se denominan controles biométricos, cuyo tratamiento de datos se encuentra significativamente limitado por la normativa sobre protección de datos, si bien la misma abre paso a ciertas excepciones justificadas, entre las que se encontrarían, a nuestro juicio, las que estamos comentando en este momento ${ }^{(10)}$. A estos efectos, la voluntariedad del consentimiento como regla general cede en la regulación vigente cuando su estado de salud "puede constituir un peligro para el mismo, para los demás trabajadores o para otras personas relacionadas con la empresa"(11). No ya es sólo que los controles de verificación de si el trabajador da positivo en el contagio del virus puedan ser realizados por la autoridad pública sanitaria, sino incluso si pueden ser exigidos por el empleador a todos sus empleados, en el ejercicio de sus facultades de revisión del estado de salud del trabajador, especialmente a la vista de que los asintomáticos también pueden transmitir la enfermedad. Ciertamente, cuando está en juego el derecho a la vida y a la salud de todos, este tipo de controles resultan plenamente justificados, pero ello debe conciliarse con el derecho a la privacidad del trabajador y, por ende, deberán establecerse los necesarios protocolos en cuanto al modo de realizarlos y a la gestión de las bases de datos que se traten y mantengan al efecto.

(8) Artículo. 8 Real Decreto 463/2020, de 14 de marzo (BOE 14 de marzo).

(9) Véase Ministerio de Sanidad (2020). Procedimiento de actuación para los servicios de prevención de riesgos laborales frente a la exposición al SARS-CoV-2. https://www.mscbs.gob.es/profesionales/saludPublica/ccayes/alertasActual/nCov-China/documentos/ Proteccion Trabajadores SARS-CoV-2.pdf.

Un comentario a ello en Mercader, J. (2020). ¿Quién puede controlar la temperatura de los trabajadores? Comenzando a pensar en el desescalado, Foro de Lab

(10) Artículo.9.2 incisos b y h Reglamento UE 2016/679, de 27 de abril (DOUE 4 de mayo), relativo a la protección de las personas físicas en lo que respecta al tratamiento de datos personales y a la libre circulación de estos datos.

(11) Artículo 22 Ley 31/1995, de 8 de noviembre (BOE 10 de noviembre), de Prevención de riesgos Laborales, en conexión con la disposición adicional. 17 $7^{\text {a }}$ Ley Orgánica 3/2018, de 5 de diciembre (BOE 6 de diciembre), de protección de datos personales y garantía de los derechos digitales. 
Como contrapunto a lo anterior, como algo claramente diferenciado a los controles de salud, se encontraría la hipótesis de solicitar al trabajador un certificado de inmunidad frente al virus, a modo de lo que se ha venido denominando el "pasaporte de inmunidad", particularmente delicado en la hipótesis de que está práctica se extienda en los momentos de desarrollo de los procesos de contratación laboral. Esta es una práctica que, a nuestro juicio, iría frontalmente contra la normativa europea y nacional en materia de protección de datos personales, sin perjuicio de que, como excepción ello, pudiera ser admisible para ciertos trabajos para los cuales el trabajador debe superar determinadas condiciones de salud y ausencia de riesgos de diseminación de contagios víricos en particular ${ }^{(12)}$.

\section{Efectividad y eficacia de las medidas legislativas}

Uno de los rasgos más extendidos entre la legislación laboral reside en la dificultad de que sus reglas resulten de real aplicación y cumplimiento (efectividad), así como que cumpliéndose logren sus objetivos y fines (eficacia) (13) Más allá de la obligada hermenéutica más formal de análisis de las normas jurídicas, al estudioso le corresponde adentrarse en la no fácil tarea de comprobar hasta qué punto las normas laborales se cumplen efectivamente, del mismo modo que diagnosticar si el proceso aplicativo de la norma ha desembocado en el logro de los objetivos que realmente pretendía el legislador con ello(14).

Desde esta perspectiva, la contundencia de las normas laborales aprobadas en el contexto de un escenario de crisis sanitaria de esta envergadura, así como de la intensidad de los controles desarrollados para asegurar su cumplimiento, permiten adelantar que el grado de cumplimiento y de eficacia de las medidas adoptadas ha sido casi universal. Naturalmente, en este contexto hay que diferenciar entre eficacia de la finalidad central y de los fines instrumentales para lograr la anterior, en el sentido de que la finalidad central no es otra que el confinamiento de la población con vistas a lograr la contención de la diseminación del virus, mientras que el objetivo instrumental lo constituye lo pretendido con las medidas laborales orientadas a lograr dicho confinamiento, así como con las medidas sociales dirigidas a contrarrestar los efectos negativos derivados de la pérdida de ingresos a resultas de la paralización de la actividad empresarial provocada igualmente para asegurar el confinamiento.
Pues bien, centrados en las medidas laborales y sociales, puede afirmarse, en una primera aproximación, que su nivel de eficacia ha sido considerablemente elevado. Desde el punto de vista laboral, la aplicación de la prioridad del teletrabajo y la centralidad adquirida por el procedimiento de suspensión del contrato de trabajo resulta indiscutible, mientras que desde el punto de vista social ha resultado igualmente plenamente efectiva la ampliación de las prestaciones de Seguridad Social a ciertos colectivos que con la regulación establecida hasta ahora no percibirían prestaciones económicas. Se trata de medidas de enorme envergadura en cuanto a su implementación, tanto desde el punto de vista de los trabajadores que se han visto afectados por las mismas, como desde la perspectiva de las cantidades destinadas a la ampliación de la protección social de estos trabajadores, incluidos los medios materiales y personales puestos al servicio de la gestión administrativa de tales medidas. Eso sí, un análisis más profundo y completo de la efectividad y eficacia de las medidas laborales y sociales requiere también señalar algunos aspectos que matizan e incluso pueden llegar a corregir la conclusión precedente.

Por lo que se refiere al teletrabajo, más allá de la declaración formal como una cuasi obligación de empleador y trabajador de adaptarse a un régimen de trabajo a distancia en la medida en que técnica y económicamente ello sea posible, así como de alguna flexibilización en el cumplimiento de las exigencias relativas a la prevención de riesgos laborales, la normativa ha establecido pocas novedades. De este modo, esas pocas novedades es difícil que hayan sido las determinantes de un efecto tan impactante como el de que varios millones de trabajadores en un tiempo muy breve hayan pasado a ejecutar su prestación en régimen a distancia. Posiblemente el cambio ha derivado normativamente sobre todo de la regla de orden público que ha impuesto

(12) Véase. Cruz Villalón, J. (2019). Protección de datos personales en el proceso de contratación: facultades y límites de actuación del empleador. Bomarzo.

(13) Véase. Cruz Villalón, J. (coord.) (2011). Eficacia de las normas laborales desde la perspectiva de la calidad en el empleo. Tirant lo blanch.

(14) Véase. Cruz Villalón, J. (2016). La metodología de la investigación en el Derecho del Trabajo. Temas Laborales, $132,73-121$. 
el confinamiento, unido a los esfuerzos por parte de las empresas de no provocar la paralización total de su actividad productiva. A la postre, puede afirmarse que la eficacia de la medida ha residido más en la capacidad tecnológica de las empresas y, en concreto, en el grado de digitalización de sus medios técnicos y productivos, que son los que han propiciado un cambio organizativo de tanto calado como el que se ha producido y además en un lapso de tiempo tan breve. Dos matices importantes adicionales han de ser introducidos al respecto. Primero, que una cosa es que se haya extendido a muchos empleados el régimen del teletrabajo y otra diferente, difícil de ponderar, es hasta qué punto ello ha logrado realizarse con grados de eficiencia y productividad suficiente para las empresas. Segundo, que el proceso de cambio ha sido más fácil entre las grandes empresas, mientras que ha sido más complejo y difícil entre las pequeñas y micro empresas.

En cuanto a la canalización preferente de las interrupciones del trabajo a través de los procedimientos de suspensión de los contratos de trabajo, con vistas a contener los despidos también la eficacia de la medida requiere de dos precisiones de notable importancia. Por un lado, ha de tenerse presente que, a pesar del número tan elevado de trabajadores afectados por las suspensiones de contrato, también ha sido muy intenso el número de extinciones contractuales detectadas a partir de la declaración del estado de alarma. En particular, la suspensión contractual no ha sido vehículo de contención de las denuncias ante tempus de los contratos temporales, de modo que más de medio millón de contratos de trabajo temporales se han extinguido en apenas quince días. Ello no constituye ninguna novedad, sino que muestra una vez más el uso desviado de la contratación temporal dentro de nuestro ordenamiento jurídico nacional, cómo se utiliza más como instrumento de ajuste de empleo ante las situaciones de crisis que como institución destinada a atender las necesidades de trabajo coyunturales en la actividad empresarial.

Por otro lado, la eficacia real de la suspensión contractual ante la emergencia sanitaria sólo se podrá diagnosticar debidamente cuando transcurra el ciclo completo de reactivación económica y, en la medida en que la misma se verifique una cierta inmediatez y celeridad. En concreto, lo que está por ver es si, una vez levantado el estado de alarma, es posible retornar a un escenario de vuelta dentro de un tiempo razonablemente breve al nivel de actividad empresarial precedente a la emergencia sanitaria. Lo que se puede señalar en el momento de cierre de este trabajo, es que a mediados de julio de los 3,4 millones de trabajadores que se han visto afectados por una suspensión del contrato de trabajo durante el estado de alarma, se han llegado a reintegrar a sus puestos de trabajo del orden de la mitad de ellos y todavía la otra mitad se encuentra en la incertidumbre de si podrán reincorporarse en el corto plazo o acabarán por ser despedidos. Desde luego, que se desemboque en uno u otro escenario respecto de los que todavía están en la expectativa de reincorporarse o verse despedidos dependerá de muchos factores, probablemente los más relevantes ajenos a las medidas legislativas laborales adoptadas o que se puedan adoptar.

Ciertamente se han adoptado medidas legislativas en este orden, como reducir los costes empresariales en las cotizaciones sociales empresariales si se produce la reincorporación al trabajo, la declaración como injustificado de un despido intentando motivarlo en los efectos laborales de la paralización de la actividad económica por la pandemia, la prohibición de realizar horas extraordinarias, de incrementar los procesos de tercerización o de realizar nuevas contrataciones laborales hasta tanto no se hayan reincorporado todos los trabajadores con sus contratos en suspenso. En todo caso, este tipo de medidas tienen un impacto limitado en la práctica, pues el margen de gestión del mercado de trabajo por parte de la norma laboral aisladamente considerada en este escenario resulta claramente limitada: a nuestro juicio, parece indiscutible que el panorama de futuro se decante más por la recuperación de la situación precedente que por una fuerte destrucción de empleo puede depender sobre todo de políticas económica generales, más de carácter extralaboral, sin perjuicio de que también serán necesarias medidas adicionales que propicien una más fácil transición desde la paralización profunda de la economía a su necesaria progresiva recuperación.

En lo que se refiere a las medidas sociales adoptadas, en concreto las relativas a la ampliación de la cobertura de las prestaciones de Seguridad Social, especialmente desde el punto de vista subjetivo, puede afirmarse que se han detectado bastante bien los ámbitos en los que la regulación precedente dejaba fuera de la acción protectora a importantes grupos de trabajadores que veían interrumpidos sus ingresos a resultas de la imposibilidad de seguir trabajando: trabajadores sin el período de cotización suficiente para percibir la prestación por desempleo (tanto a efecto de la suspensión de los contratos de trabajo como de las extinciones de los contratos temporales), personal del servicio doméstico 
no protegido frente al desempleo, trabajadores autónomos que cesan en su actividad o que ven intensamente reducidos sus ingresos. Incluso, en términos intuitivos, si bien ello requerirá en su momento realizar la valoración más ajustada, se puede barruntar que la eficiencia de estas medidas ha sido bastante notable, entendido el término eficiencia en la noción clásica de los economistas de la relación existente entre el costo de una medida y el impacto material que la misma tiene en orden a lograr el objetivo pretendido con la misma.

Eso sí, también en este terreno se han detectado ciertas bolsas de población marginal que han quedado fuera, cuando menos hasta el momento presente, de ser atendidas frente a una situación de necesidad surgida una vez más a resultas de la paralización de la actividad económica. Se trata de bolsas de población que ya con anterioridad detectaban insuficiencias en su atención por el conjunto del sistema de protección social, derivado bien lo sea por su ubicación en el ámbito de la economía informal, por sus fuertes responsabilidades familiares que sólo le permite una incorporación marginal al mercado de trabajo, o bien por la mera realización de micro empleos que lo sitúan dentro del perfil de los denominados como trabajadores pobres. Todo ello ha provocado la ya mencionada aprobación de un Ingreso Mínimo Vital como nueva prestación económica de la Seguridad Social, para hacer frente especialmente a la situación de extrema pobreza, con particular atención a la pobreza infantil.

\section{Unas medidas para la emergencia: una normativa transitoria}

Uno de los rasgos caracterizadores más destacados de las medidas laborales y sociales adoptadas con ocasión del estado de alarma reside en el dato de tratarse de medidas "para" la emergencia, adoptadas "ante" la emergencia.

Es importante resaltar la diferencia frente a actuaciones del pasado, incluso algunas de ellas en las que se utilizaba una expresión muy similar como era la de Derecho del Trabajo "de" la emergencia, para reaccionar precisamente a un escenario crítico en la evolución del empleo y del mercado de trabajo. En muchas otras ocasiones, incluso diríamos en la mayoría de las ocasiones, las reformas laborales más profundas y de carácter estructural se han producido como reacción frente a un proceso de intenso deterioro del empleo. Ahora bien, en esta ocasión nos encontramos ante un contexto cualitativamente diferente, por mucho que haya ese elemento común de una fuerte tendencia a la destrucción del empleo. Lo cualitativamente diferente es que ahora se trata de reaccionar frente a una causa externa a lo económico situada en el terreno de la tutela del derecho a la salud, en tanto que en las situaciones precedentes se actuaba frente a escenarios depresivos del ciclo económico, donde, por añadidura, prevalecía una idea de que la rigidez de la norma laboral era un obstáculo no sólo para hacer frente a la crisis de empleo y a la sucesiva reactivación de la economía; más aún, donde subyacía la consideración de que esa normativa laboral había devenido inadecuada para responder a un nuevo modelo económico más globalizado, competitivo, más cambiante en situaciones incluso de crecimiento del ciclo económico $y$, por ende, necesariamente más flexible. En definitiva, las experiencias precedentes de reformas legislativas, por mucho que se afirmase que se adoptaban en el marco "de" la emergencia, acababan no siendo unas reformas "para" la emergencia", sino que se incorporaban para quedarse y, como tales, se hacían estructurales para un nuevo marco estable del ordenamiento laboral.

Como contrate a ello, las medidas laborales, pero también las de Seguridad Social adoptadas, no es sólo que formalmente se presenten como actuaciones "para" la emergencia, sino que, en correspondencia con ello, su configuración jurídica es de manera prácticamente universal para tener una vigencia muy limitada en el tiempo, sin pretender efectuar modificación alguna a los textos de nuestra legislación laboral. Dicho plásticamente, las medidas en su conjunto constituyen una gran "disposición transitoria", llamadas a agotarse en su vigencia apenas se supere la situación de emergencia derivada de la declaración del estado de alarma. De manera expresa así lo indican todas las medidas tanto laborales como de Seguridad Social, o bien, cuando así no se indica en el precepto concreto a través del cual se introduce la reforma, sí que lo hace la concreta norma en la que se incorpora, norma ésta en su totalidad de vigencia limitada en el tiempo.

Por añadidura, conviene recordar que este Gobierno de coalición recién acababa de tomar posesión e iniciar una legislatura, donde se contemplaban unos compromisos de reforma de la legislación laboral, no sólo orientada a corregir la normativa introducida por la reforma laboral de 2012 en el contexto de la última crisis económica, con la que manifestaba su oposición, sino que pretendía acometer todo un ambicioso proyecto de elaboración de un "nuevo" Estatuto de los 
Trabajadores ${ }^{(15)}$. Lo más destacable a estos efectos es que en ningún caso, salvo algún aspecto muy secundario (en concreto, lo relativo a la determinación del interlocutor en representación de los trabajadores en las consultas en los expedientes temporales de suspensión por causas económicas $\left.{ }^{(16)}\right)$, ninguna de las medidas adoptadas se conecta con los elementos proyectados de reforma estructural de la legislación laboral contenidos en el acuerdo de programa de Gobierno de la coalición de partidos actual. Más aún, puede afirmarse que el escenario de emergencia ha provocado una completa paralización de la implementación de las reformas legislativas estructurales que se pensaban adoptar.

\section{Elementos de posible impacto estructural}

Eso sí, ese carácter de gran "disposición transitoria" que caracteriza al conjunto de las medidas laborales y sociales adoptadas, puede que no se detenga por completo en un resultado de impacto limitado en el tiempo de las medidas. Más que las medidas en sí mismas, lo que se advierte es que el escenario presentado posiblemente va a tener una proyección en el tiempo desde la perspectiva del empleo mayor de la inicialmente esperada y, sobre todo, que la implementación de las medidas ha evidenciado en la práctica ciertas deficiencias de nuestra normativa. Se trata de unas deficiencias que con seguridad auguran cuando menos un debate con proyección más en el largo plazo; debate que puede dar lugar a reformas de carácter estructural, que, por añadidura, alguna de ellas ni siquiera se encontraban dentro de la relación de modificaciones incluidas dentro del actual programa de gobierno.

Por mencionar sólo dos de los aspectos más señalados, uno en el ámbito de lo laboral y otra en el ámbito de lo social, merece la pena destacar los siguientes.

Por lo que refiere al ámbito laboral, se han detectado de manera inmediata las insuficiencias y la manifiesta pobreza de la normativa existente en torno al teletrabajo. El cambio en las empresas a estos efectos ha sido tan vertiginoso y ha manifestado algunas ventajas cualitativas, que es previsible un protagonismo muy superior del trabajo a distancia en nuestras empresas. Para que con seguridad esa expansión no se produzca en los términos en los que se ha desarrollado durante el estado de alarma, que determina una fórmula excepcional de teletrabajo a distancia a tiempo completo, sino que es previsible se extiendan fórmulas intermedias de trabajo semipresencial o semi a distancia; en todo caso, de fórmulas para las que se advierte la clara insuficiencia de la regulación actual ${ }^{(17)}$. De igual forma, la amplia expansión de los procedimientos de suspensión de los contratos de trabajo ha manifestado el alto consenso en cuanto a su utilidad en situaciones de crisis temporales de empleo, lo que puede aconsejar una adaptación con más precisión de algunos de sus aspectos regulativos.

Por lo que afecta a las medidas sociales, ya hemos señalado cómo se han detectado bolsas de población desasistida por la actuación integrada de la acción protectora de la Seguridad Social junto con la intervención de las Comunidades Autónomas en materia de Asistencia Social, cuando menos de un tratamiento de garantía de umbrales mínimos comunes para todos los territorios, que ha provocado la decisión de completar las prestaciones no contributivas de Seguridad social de manera permanente, por vía de la introducción del Ingreso Mínimo Vital. Se trata de una medida que perfila con precisión las situaciones de necesidad a las que se pretende hacer frente, para garantizar que sus destinatarios sean aquellas personas y hogares que efectivamente lo precisan, estableciendo las necesarias reglas a efectos de conjurar riesgos tanto de que estos beneficiarios queden atrapados en el desempleo o subempleo, así como de no provocar un efecto indirecto indeseado de anclaje de estas personas en la economía informal.

(15) Para más información véase. Cruz Villalón, J. (2020). Hacia un nuevo Estatuto de los Trabajadores. Revista Trabajo y Derecho, 63, 28-ss.

(16) En concreto, el cambio consiste en que para aquellas empresas y centros de trabajo donde no se hayan celebrado elecciones de designación de comités de empresa y delegados de personal, la obligada consulta con los representantes de los trabajadores para estas suspensiones contractuales se articulaba a través de una representación designada 'ad hoc' de manera directa por la planilla de los trabajadores y con escasa intervención de los sindicatos. La modificación consiste en otorgar más protagonismo a los sindicatos más representativos en la designación de estos representantes y, con ello, establecer unos interlocutores más auténticos ante la dirección de la empresa en este procedimiento de consultas.

(17) Véase. Cruz Villalón, J. (2020). Teletrabajo y coronavirus: de la emergencia a la permanencia. Derecho de las Relaciones Laborales, $4,406-418$ 


\section{El uso generalizado del Real Decreto-Ley}

En clara correspondencia con el carácter de emergencia, inesperadamente sobrevenida y que requiere de la adopción de cambios legislativos urgentes, que, por añadidura, afectan a materias para las que rige la correspondiente reserva de ley, las medidas tanto laborales como sociales adoptadas se producen todas ellas a través del instrumento del Real Decreto-Ley. Debe tenerse en cuenta, además, que esta práctica de introducir reformas laborales en escenarios de crisis económicas por vía de Real Decreto-Ley tiene una larga tradición entre nosotros, en las más de las ocasiones avaladas por nuestro Tribunal Constitucional, de modo que se trata de un fenómeno al que estamos bastante acostumbrados en el ámbito de la legislación laboral, por mucho que en reiteradas ocasiones resulta abusivo y contrario al protagonismo que le debe corresponder al Parlamento y el resto de instituciones que colaboran en el proceso de elaboración normativa.

Es cierto que lo anterior no es referible a las normas de urgencia que estamos analizando en el presente estudio. A pesar de que el poder ejecutivo en reiteradas ocasiones ha adoptado una actitud claramente expansiva del uso del instrumento del Real Decreto-Ley, en muchas ocasiones forzando el cumplimiento de los requisitos exigidos constitucionalmente para poder adoptar una norma de esta naturaleza, con toda seguridad se puede afirmar que en esta ocasión nos encontramos ante una situación fáctica y frente a un tipo de cambios legales para los que queda plenamente justificado el uso del Real Decreto-Ley. En otros términos, se trata de un uso del Real Decreto-Ley que se atiene sin ninguna duda a los requisitos constitucionales, tanto en su vertiente formal (extraordinaria y urgente necesidad) como material del tipo de materias objeto de atención (artículo 86.1 $\mathrm{CE}$ ). En esta ocasión, las sucesivas exposiciones de motivos con clara contundencia y facilidad aportan las razones que avalan en estos casos la aprobación de las medidas por medio de la vía del Real Decreto-Ley.

Por lo demás, constituye práctica muy habitual en la técnica legislativa, de nuevo reiterado en las reformas laborales de urgencia, que la convalidación del correspondiente Real DecretoLey venga sucedido de un acuerdo de la mesa del Congreso de los Diputados por medio del cual su tenor es convertido en un proyecto de ley. Proyecto de Ley que, a partir de ese instante, se somete al procedimiento ordinario de tramitación parlamentaria $y$, con ello, recuperando el Parlamento su plena capacidad legislativa, especialmente por lo que supone de posibilidad de enmendar el texto inicial del Gobierno. Pues bien, por lo que afecta a las medidas laborales y sociales, la práctica totalidad de los Reales Decretos-Ley citados han sido transformados en proyectos de Ley ${ }^{(18)}$. No obstante, salvo para algún asunto puntual, la decisión de conversión tiene un alcance más simbólico o de valor político, por cuanto que es bastante previsible que tales iniciativas van a decaer a lo largo de su tramitación parlamentaria. En efecto, por acelerada que sea dicha tramitación parlamentaria y a pesar, por tanto, de que haya decidido tramitarse con atribución de competencia plena a la Comisión del Congreso correspondiente por el procedimiento de urgencia, lo más probable es que el levantamiento del estado de alarma provoque la pérdida de vigencia de la práctica totalidad de las medidas, con lo cual carezca de sentido una aprobación de una Ley ordinaria con contenido vacío en su dinámica temporal y sin posibilidades de que a las medidas se le atribuyan efectos retroactivos. La plena transitoriedad de las medidas así lo augura.

\section{Con alguna precisión reglamentaria menor, pero desorbitante}

Otro de los elementos más significativos, por lo llamativo y singular desde el punto de vista de las Fuentes del Derecho, es el recurrente uso que se ha hecho de decisiones de rango reglamentario inferior, como es el acudir de manera muy recurrente a la aprobación de Órdenes Ministeriales, a través de las cuales se desarrolla el contenido tanto del Real Decreto de estado de alarma como de los Reales Decretos-Ley, a través de las que se implementa este último. Incluso a veces se trata de decisiones que presentan dudas de su carácter reglamentario, en la medida en que se dictan por medio de simples Resoluciones de órganos administrativos inferiores al propio Ministro. A mayor abundamiento, se trata de una actuación conforme a la delegación a los cuatro Ministerios designados como autoridades competentes delegadas: Defensa, Interior, Transportes y Sanidad ${ }^{(19)}$. Por tanto, esa

(18) En el momento de redactar el presente trabajo ya se había adoptado por la Mesa del Congreso la decisión de conversión en Proyecto de Ley respecto de los Reales Decretos-Ley 8/2020, 9/2020, 10/2020, 11/2020, 13/2020, 15/2020, 16/2020, 18/2020 y 20/2020.

(19) Artículo 4 Real Decreto 463/2020, de 14 de marzo (BOE 14 de marzo), por el que se declara el estado de alarma para la gestión de la situación de crisis sanitaria ocasionada por el COVID-19. 
profusión de Órdenes Ministeriales en ningún caso se produce respecto del Ministerio de Trabajo y Economía Social, si bien es cierto que las aprobadas por los Ministerios mencionados sí que inciden en algunos casos de manera directa o indirecta sobre el desarrollo o el impedimento del trabajo en determinados sectores $^{(20)}$

Una vez más, esta actuación sólo se puede contemplar desde la perspectiva de la situación de emergencia derivada de la declaración del estado de alarma, por tanto, entendido como una actuación excepcional y transitoria, que en modo alguno puede marcar un precedente al objeto de deslegalizar cierto tipo de materias, ni tampoco de reducir las exigencias de que el ejercicio de la potestad reglamentaria con carácter general le corresponde al Consejo de Ministros, a través de la aprobación de los correspondientes Reales Decretos. Especialmente es obligado tener en cuenta que constitucionalmente la reserva de ley ordinaria se encuentra perfectamente delimitada y no puede ser eludida en situaciones de excepcionalidad, como son los estados de alarma, cuyo respeto se puede canalizar en todo caso a través del instrumento del Real Decreto-Ley. A mayor abundamiento, debe tenerse presente que constitucionalmente la potestad reglamentaria la ejerce el Gobierno (artículo $97 \mathrm{CE}$ ), que está compuesto por el Presidente, Vicepresidente, de los Ministros y de los demás miembros que establezca la Ley. A estos efectos, ninguna Ley en estos términos ha ampliado la composición del Gobierno más allá de lo previsto constitucionalmente ${ }^{(21)}$. A tenor de ello, si bien los Ministros, a través de órdenes Ministeriales pueden aprobar disposiciones de carácter reglamentario, que en modo alguno pueden invadir la reserva de Ley Ordinaria constitucionalmente establecida, ello no cabe realizarlo por vía de Resoluciones administrativas por parte de autoridades ministeriales inferiores al Ministro. A tenor de todo lo anterior, debe concluirse necesariamente que en algunos casos se han producido indiscutibles excesos, que no pueden justificar ni la excepcionalidad del momento ni la urgencia en la adopción de cierto tipo de decisiones, bien porque han sido adoptadas por parte de autoridades inferiores al Ministro, bien porque adoptadas por vía de Orden Ministerial han invadido el territorio correspondiente a la reserva de ley ordinaria, en los términos constitucionalmente previstos ${ }^{(22)}$. Por último, no está de más destacar que en lo que afecta a la legislación laboral en España el espacio normativo asumido por las disposiciones reglamentarias, como criterio general, es muy reducido, en la medida en que se prevé que "las disposiciones reglamentarias desarrollarán los preceptos que establecen las normas de rango superior, pero no podrán establecer condiciones de trabajo distintas a las establecidas por las leyes a desarrollar" (artículo $3.2 \mathrm{ET})^{(23)}$.

\section{Imprecisión normativa y sucesiva interpretación administrativa: ¿técnica de soft law?}

Resulta cada vez más habitual que la técnica jurídica de redacción de los textos legales adolezca de dosis elevadas de falta de precisión en el mandato legal, lo que como efecto derivado provoca una enorme incertidumbre legislativa, con efectos negativos sobre la seguridad jurídica como uno de los principios informadores básicos de cualquier Estado de Derecho (artículo 9.3 CE) $)^{(24)}$. No cabe la menor duda de que

(20) Véase a título de ejemplo la prohibición de desarrollo de actividades de construcción o de reparación en las viviendas o locales donde estén presentes personas ajenas a la obra (OM SND de 12 de abril, BOE 12 de abril), o bien a la exención temporal del cumplimiento de las normas de conducción y descanso en los transportes de mercancías (Resolución de la dirección General de Transporte Terrestre de 14 de abril de 2020, BOE 15 de abril).

(21) Artículo 1 de la Ley 50/1997, de 27 de noviembre (BOE 28 de noviembre), de Gobierno.

(22) Por poner un ejemplo concreto, véase. La Orden Ministerio Sanidad SND/458/2020, de 30 de mayo (BOE 30 de mayo), para la flexibilización de determinadas restricciones de ámbito nacional establecidas tras la declaración del estado de alarma en aplicación de la fase 3 del Plan para la transición hacia una nueva normalidad, cuyo artículo 3 establece medidas regulativas del teletrabajo que no le competen abordar al Ministerio de Sanidad y mucho menos a través de una disposición de rango tan bajo modificando normas de rango jerárquico superior.

(23) Véase. Valdés Dal-Ré, F. (1989). La potestad reglamentaria en el ordenamiento laboral. Revista Española de Derecho Constitucional, 26.

(24) Baste con citar algunos ejemplos elocuentes a estos efectos: ¿quiénes son los sujetos afectados y cuáles son los efectos y alcance del compromiso de mantenimiento del empleo a las empresas que acudan a las medidas extraordinarias en el ámbito laboral legalmente previstas?; ¿se establece un deber formal tanto para empleador como para trabajadores de adaptar su actividad a un régimen de trabajo a distancia?; estableciéndose el carácter voluntario de la autoevaluación de riesgos laborales por parte del trabajador a distancia, ¿qué consecuencias tiene la ejecución del trabajo a distancia sin tal autoevaluación, especialmente para el empleador?; ¿resulta de aplicación la regla general del silencio administrativo cuando se supera el plazo máximo de cinco días para que la autoridad laboral dicte resolución de constatación de la fuerza mayor respecto de los procedimientos de suspensión de 
en ocasiones resulta imprescindible que el legislador acuda al uso tan extendido de conceptos jurídicos indeterminados, que siempre aportan un halo de incertidumbre necesario para lograr contemplar un amplio abanico de situaciones, lo que no aconseja una rigidez en la objetivización de los supuestos de hecho determinantes de la aplicación de la regla laboral; fenómeno este que puede resultar plenamente compatible con las exigencias constitucionales de seguridad jurídica. Pero, en este caso no nos estamos refiriendo al uso de la técnica de los conceptos jurídicos indeterminados, sino de otro tipo de defectos técnicos de mayor gravedad, que provocan auténticas situaciones de inseguridad jurídica, difícilmente justificables.

Esta inseguridad jurídica, a su vez, da lugar en unas ocasiones a un incremento de la litigiosidad judicial y en otros casos a una intensificación del margen de actuación de la Administración laboral en su labor de ejecución de la legislación laboral y, en todo caso, coloca a los destinatarios de esas normas en una posición de notable dificultad a la hora de decidir cómo adaptan sus comportamientos a los efectos de un correcto cumplimiento de las medidas legislativas adoptadas. Analizada desde esta perspectiva, la de redacción de las normas aprobadas para introducir las medidas laborales y sociales de actuación frente a la emergencia sanitaria, puede afirmarse que en este caso este tipo de imprecisiones técnicas se perciben como más reiteradas, incluso cabe aventurar que, en algunos casos, conscientemente introducidas por el legislador y no atribuibles a la mera celeridad con la que se ha producido la elaboración de estas medidas legislativas.

Es cierto que, en varios de estos supuestos, una labor hermenéutica integrativa del conjunto del ordenamiento jurídico, más o menos sencilla, permite dar respuesta a algunos de los interrogantes previamente identificados. Ahora bien, incluso en algunos casos en los que a mi juicio personal la respuesta resultaría sencilla e indiscutible, se pueden detectar opiniones doctrinales de contrario, que ya de por sí muestran los riesgos de legislar de este modo.

Esta conducta que, por lo demás es recurrente en muchas ocasiones en la técnica regulativa entre nosotros desde hace ya bastante tiempo, tiene consecuencias más graves en la coyuntura actual, por diversas razones acumuladas: unas medidas que se van a aplicar en masa a un número muy elevado de supuestos; medidas que se van a implementar de manera inmediata; medidas que tienen consecuencias muy graves para las empresas y trabajadores en caso de no acertar en la interpretación correcta; medidas cuya implementación en ocasiones se lleva a cabo a través de una intervención por parte de la Administración laboral en el ejercicio de sus facultades de ejecución de la legislación laboral que, como se sabe, se encuentra transferida a las Comunidades Autónomas, lo que añade incertidumbre a resultas de que la interpretación de la normativa corre el riesgo de que sea diferencia por parte de cada autoridad autonómica; y, finalmente, porque el canal ordinario de superación de la incertidumbre vía la conformación de una asentada jurisprudencia por parte del Tribunal Supremo se producirá tras un largo período aplicativo de las medidas, en la práctica totalidad de los casos cuando dicha normativa ya se encuentre derogada.

Consciente de la imposibilidad de esperar a una unificación de doctrina interpretativa por parte de los Tribunales de Justicia, se ha acudido a otra fórmula, cuya significación conviene resaltar. Me refiero, en concreto, a una actuación en la mayoría de los casos por parte de la Administración laboral, que a través de diversos instrumentos ofrece la que a su juicio es la interpretación más adecuada. Desde luego, ello se puede producir frente a muchos de los interrogantes inicialmente señalados, pero no en todos los casos.

A tal efecto, en unas ocasiones, la Administración ha aprobado Guías orientativas o protocolos de actuación, que se sitúan en el territorio típico de los

\footnotetext{
los contratos de trabajo?; en caso de contratos de obras y servicios concertadas con las Administraciones Públicas, la suspensión del contrato administrativo pero con el deber impuesto a la Administración contratante de compensar a la contratista por los gastos salariales efectivamente abonados ¿supone imposibilidad de suspender estos contratos de trabajo por causas de fuerza mayor o económicas?; en el caso de suspensiones de contratos de trabajo por causas económicas, cuando no hay representantes de los trabajadores elegidos en la empresa, ¿cómo debe gestionarse la constitución de la comisión negociadora prevista legalmente? ¿la declaración de que no constituye causa justificativa para despedir ante causas justificadas de suspensión con motivo del Covid 19, supone que en caso de que se despida estamos ante un despido improcedente o nulo?; ¿Qué efectos tiene la interrupción del cómputo de la duración máxima de los contratos temporales sobre hechos sobrevenidos posteriormente de llegada del término o cumplimiento de la condición resolutoria para ciertos contratos de duración determinada que manifiestan desaparición de la causa justificativa de la contratación temporal?; las empresas sometidas al régimen del permiso obligatorio retribuido recuperable en esas situaciones ¿pueden optar alternativamente por suspender los contratos de trabajo?; ¿hasta cuándo se extiende el subsidio extraordinario por falta de actividad para los empleados de hogar?.
} 
instrumentos de "soft law". Desde el punto de vista práctico sí que se trata de documentos de una trascendencia muy superior a lo que suponen desde el punto de vista formal. En efecto, dichas Guías o Protocolos funcionan como importantes pautas orientativas de actuación para las empresas, que no puede descartarse que después las utilicen a efectos de justificar su comportamiento, especialmente relevante en una hipótesis de apertura de un expediente sancionador en el ámbito administrativo. Más aún, incluso el seguimiento de dichas pautas puede servir de importante asidero argumental posterior en sede judicial, caso de que sus decisiones se judicialicen en el ámbito del orden social de la jurisdicción.

En ese marco, también han sido relevantes las cuestiones planteadas por particulares, que han dado lugar a respuestas formales por parte de la propia autoridad laboral, en términos de criterios interpretativos por vía de un oficio, casi siempre por parte de la Dirección General de Trabajo del Ministerio de Trabajo y Economía Social, siempre resaltando que tales criterios tienen "un mero carácter informativo".

Se trata nuevamente de instrumentos que cabría incardinar en la categoría de fórmulas de "soft law" que, a pesar de su naturaleza menor dentro de cualquier sistema jurídico, desde el punto de vista material y práctico están adquiriendo una enorme relevancia, tanto por lo que suponen de unificación posterior de la actuación administrativa aplicativa de toda esta normativa, como de pauta interpretativa influyente en la práctica para los Tribunales de Justicia. Posiblemente no se trata del instrumento más deseable para dar respuesta a algunos de los interrogantes tan significativos enumerados al principio de este apartado, pero teniendo en cuenta el importante juego que han tenido en este caso y, probablemente, su afianzamiento de futuro en la fase post-emergencia, cuando menos serían exigibles procedimientos de amplia transparencia pública de este tipo de instrumentos. En concreto, sería oportuno que todo este tipo de actuaciones "intra-administrativa" o de respuesta individualizada a ciertos particulares, encontrase un vehículo oficial de conocimiento por parte de todos, a los efectos de que el conjunto de los destinatarios de las normas correspondiente pueda tener un conocimiento preciso de este tipo de interpretaciones administrativas, por lo que suponen de orientación de la actuación de la Administración en el ejercicio de sus competencias, como incluso de instrumento de sucesiva defensa judicial.

\section{La intervención judicial de ejercicio de la actividad jurisdiccional}

A pesar de la siempre más que relevante trascendencia de la intervención de los Juzgados y Tribunales de Justicia, en este caso la gran dificultad de su actuación en relación con las medidas laborales y sociales se encuentra en que su intervención de unificación doctrinal es lenta y en este caso lo será claramente tardía. A mayor abundamiento, el propio estado de alarma ha provocado una importante paralización de muchas actuaciones judiciales, sin perjuicio de que hayan tenido un papel destacado respecto de algunos asuntos de urgencia, que no permitían demora en el contexto de la emergencia sanitaria. Llama la atención que hasta el último momento no se hayan adoptado medidas específicas frente al colapso judicial( ${ }^{(25)}$, más allá de las adoptadas en el terrero de la gestión por parte del Consejo General del Poder Judicial(26).

La actuación más relevante a estos efectos se ha producido a resultas de demandas y recursos presentados frente a las Administraciones Públicas, especialmente frente a las competentes en materia de gestión de la asistencia sanitaria pública, en orden a las medidas especiales que se deberían adoptar para proteger frente al posible contagio del virus por parte del personal sanitario. Se trata de una actuación que en muchas ocasiones ha venido precedida por denuncias ante la Inspección de Trabajo, que ha desplegado una labor encomiable de asesoramiento y vigilancia de la salud en momentos tan delicados y complejos, pero que igualmente en paralelo ha provocado la existencia de importantes resoluciones judiciales en esta materia. Se trata de decisiones judiciales que en algunos casos se han adoptado como medidas cautelares en unos procesos que no permitían desarrollar

(25) Real Decreto-Ley 16/2020, de 28 de abril (BOE 29 de abril), de medidas procesales y organizativas para hacer frente al COVID-19 en el ámbito de la Administración de Justicia. Acuerdo Comunidad Valenciana, de13 de marzo de 2020, recurso 57/2020.

(26) Para más información, véase. Instrucciones de 11 de marzo de 2020, del Consejo General del Poder Judicial, relativas a la prestación del servicio público judicial ante la situación generada por el COVID-19. file:///C:/Users/Jesús/Downloads/INSTRUCCIÓN\%20 COVID-19.pdf 
con plenitud el correspondiente proceso judicial, particularmente abordando la necesidad de suministrar equipos de protección individual para el personal sanitario(27). Desde luego, se trata de una labor encomiable abordada por los Juzgados de lo Social, en una materia ciertamente compleja y delicada, para la que no existían apenas criterios interpretativos por parte de los Tribunales Superiores.

Por otro lado, se sucederán otra serie de pronunciamientos en lo que afecta a la interpretación y aplicación de las medidas laborales, especialmente respecto de los procedimientos de suspensión de los contratos de trabajo durante la pandemia, a resultas de la autorización administrativa imprescindible en estos casos por parte de la Administración laboral al fundarse en causas de fuerza mayor, como las entidades gestoras de la Seguridad Social por las consecuencias que estos procedimientos tienen en el derecho a percibir la prestación por desempleo. A estos efectos, aunque sea algo tardía, se han establecido ciertas preferencias en la tramitación procesal de los procedimientos relacionados con el COVID-19(28).

\section{El espacio de influencia de la concertación social}

A resultas de la aprobación de las medidas a través de Reales Decretos-Ley de auténtica en un contexto de aguda emergencia sanitaria, el procedimiento legislativo ha sido acelerado al máximo, con el evidente efecto derivado de una marginalidad muy perceptible de la concertación social en la fase inicial de adaptación de las medidas.

Antes de adoptarse las medidas laborales y sociales de referencia, las organizaciones sindicales y empresariales acordaron un documento consensuado por medio del cual trasladaban al Gobierno un conjunto de medidas orientativas al respecto, solicitando que estas medidas extraordinarias fueran discutidas en el seno de la mesa de diálogo social ${ }^{(29)}$. Se trata de un documento que contenía medidas que en muchos de sus aspectos coincidían con las posteriormente adoptadas por el Gobierno: fomentos de la vía de la suspensión de los contratos de trabajo, protección de los trabajadores fijos-discontinuos, situaciones de aislamiento o contagio de las personas trabajadores, cierre de centros escolares, centros de día y restricciones de movilidad, teletrabajo. Sin haberse llegado a elevar dichas propuestas a la mesa de diálogo social, no haber existido canales informales de concertación social con el Gobierno, en la práctica las propuestas sindicales y empresariales tuvieron una importancia significativa, cuando menos respecto de las primeras medidas adoptadas. Esta circunstancia, aparte de la gravedad de la situación provocada por la diseminación del Covid-19, determinó en líneas generales un apoyo por parte tanto de las organizaciones sindicales como de las asociaciones empresariales más representativas a las medidas que se adoptaron desde el primer momento. Sucesivamente, otra serie de medidas gubernamentales fueron más criticadas, especialmente desde las esferas empresariales en el momento de acordar las medidas de reforzamiento más intenso de la paralización de la actividad económica. Me refiero en particular, a la introducción de un sistema de permisos retribuidos recuperables durante la primera quincena de abril, que recibió un fuerte rechazo por parte empresarial ${ }^{(30)}$.

Por otra parte, como un efecto reflejo derivado de lo anterior, el proceso de concertación social que se estaba

(27) A título ejemplificativo, véase. Auto TSJ, Cataluña, 2 de abril de 2020, demanda 8/2020; Auto JS, Tenerife, de 23 de marzo de 2020 , rec. 276/2020, ECLI: ES:JSO:2020:2a; Auto JS, Guadalajara, 27 de marzo de 2020, rec. 235/2020, ECLI:ES:JSO:2020:5a; Auto JS $n^{\circ}$ 41, Madrid, 19 de marzo de 2020, res. 30/2020, ECLI: ES:JSO:2020:3A; JS n 39, Madrid, 1 de abril de 2020, rec. 370/2020, ECLI: ES:JSO:2020:21ª ; Auto JS, Castellón de la Plana, 27 de marzo de 2020, rec. 222/2020, ECLI: ES:JSO:2020:9a; Auto JS n 1, León, 27 de marzo de 2020, rec. 239/2020, ECLI: ES:JSO:2020:10a. Auto JS, Segovia n 1, 27 de marzo, rec 222/2020, ECLI: ES:JSO:2020:6a; Auto JS, Santander, 27 de marzo, rec 193/2020, ECLI: ES:JSO:2020:15a; Auto JS, Plasencia, 1 de abril de 2020, rec. 148/2020, ECLI: ES:JSO:2020:23ª; Auto JS n 5, Valladolid, 15 de abril de 2020, ECLI: ES:JSO:2020:43A. Cfr. C. Molina Navarrete, EPI para Letrados de la Administración de Justicia; no y sí para el personal sanitario: ¿dobles varas de evaluar el riesgo?, CEF, https://www.laboral-social.com/COVID-19-EPI-para-letrados-administracion-justicia-no-y-si-para-personal-sanitario-dobles-varasde-evaluar-el-riesgo.html

(28) Artículo 7.1.d Real Decreto-Ley 16/2020, de 28 de abril.

(29) Para más información, véase. Documento de propuestas conjuntas de las organizaciones sindicales, CCOO y UGT, y empresariales, CEOE y CEPYME, para abordar, mediante medidas extraordinarias, la problemática laboral generada por la incidencia del nuevo tipo de coronavirus, 12 de marzo de 2020.

(30) Real Decreto-Ley 10/2020, de 29 de marzo (BOE 29 de marzo), por el que se regula un permiso retribuido recuperable para las personas trabajadoras por cuenta ajena que no presten servicios esenciales, con el fin de reducir la movilidad de la población en el contexto de la lucha contra el COVID-19. 
desarrollando con carácter previo a la declaración del estado de alarma, orientado a las reformas estructurales de la legislación laboral en el marco de la puesta en práctica del programa del Gobierno de coalición, quedó totalmente interrumpido, en la medida en que las prioridades del conjunto de los poderes públicos e incluso sociales se habían alterado por completo.

Conforme la situación se "normalizó" desde el punto de vista de institucionalización de las decisiones políticas por parte del Gobierno, se han retomado los encuentros periódicos de celebración de la mesa de diálogo social, ahora desde la perspectiva de permitir un seguimiento del proceso de recuperación de la actividad económica y del empleo, una vez concluida la fase dura de actuación frente a la expansión del virus. Se trata de una recuperación del diálogo social que pasa a tener mayor contenido sobre todo en lo que afecta a la recuperación de la actividad productiva por parte de las empresas y, especialmente, en el modo de programar de forma paulatina la vuelta al trabajo en términos de lograr proporcionar efectividad al objetivo de reducir al máximo los riesgos de fuerte e irreversible destrucción del empleo. En definitiva, conforme la situación se "normalizó" desde el punto de vista institucional, se han retomado los procesos de diálogo social, alcanzándose dos importantes acuerdos a nivel general respecto de las medidas a adoptar para el proceso de recuperación de la actividad económica y del empleo, una vez concluida la fase dura de actuación frente a la expansión del virus. En concreto, me refiero al I Acuerdo Social en Defensa del Empleo de 11 de mayo de 2020, que sobre todo garantizó la continuidad de las medidas de protección a las suspensiones contractuales hasta finales de junio de 2020 y diseño el fomento de la reincorporación de al trabajo efectivo(31) y al II Acuerdo Social en Defensa del Empleo de 25 de junio de 2020, con medidas ampliatorias de las precedentes hasta finales de septiembre de $2020^{(32)}$.

Igualmente, el diálogo social se ha retomado en relación con las medidas de reforma legislativa ya de carácter estructural, como son emblemáticamente las relativas a la nueva regulación en materia de teletrabajo.

\section{Marginal intervención de la negociación colectiva y de la consulta a los representantes de los trabajadores en la empresa}

Igualmente, dentro del ámbito del desarrollo de la autonomía colectiva, la urgencia con la que se han tenido que adoptar todas las medidas de referencia ha provocado que también haya pasado a un muy segundo plano la intervención tanto de la negociación colectiva como del ejercicio de las facultades de consulta a los representantes de los trabajadores.

De un lado, recordar cómo una de las señas de identidad del ADN del sistema español de relaciones laborales se encuentra en el intenso diálogo entre normativa estatal y negociación colectiva, con reiteradas remisiones por parte de la Ley a la intervención de la negociación colectiva, a los efectos de que ésta última desempeñe un papel relevante en el desarrollo y aplicación al caso concreto de las medidas laborales establecidas legalmente. Pues bien, esta estrecha relación entre Ley y convenio colectivo ha desaparecido prácticamente por completo en la técnica jurídica de implementación de las medidas laborales para hacer frente al Covid-19. Cuando nos encontrábamos en una fase de recuperación del protagonismo de la negociación colectiva, tras la superación de la precedente crisis económica(33) $^{(3)}$ la necesidad de establecer una normativa de aplicación inmediata, sin poder esperar a la intermediación de complemento de la negociación colectiva, ha provocado una práctica desaparición de la intervención de los convenios colectivos, de modo que es un protagonista casi inexistente en la legislación laboral para la emergencia.

Más aún, la negociación colectiva ordinaria, que habitualmente tiene su momento más intenso en la primavera de cada año, se ha visto en la práctica suspendida en multitud de empresas e igualmente a nivel de rubro nacional. Prueba elocuente de ello es el reducido número de convenios colectivos registrados y publicados en los Boletines oficiales a partir de la declaración del estado de alarma, requisito forma de eficacia jurídica en España de los convenios colectivos. Los efectos reflejos derivados de la libre circulación dificultan con mucho la continuidad de los procesos negociales en marcha. En todo caso, no es

(31) Véase https://www.lamoncloa.gob.es/presidente/actividades/Documents/2020/110520-\%20Acuerdo\%20Social\%20en\%20defensa\%20 del\%20Empleo.pdf

(32) Véase. Baylos, A. (2020). El II Acuerdo Social en Defensa del Empleo y el Real Decreto-Ley. Nueva Tribuna. https://www.nuevatribuna. es/articulo/actualidad/ii-acuerdosocial-defensa-empleo-rdl-24-2020-26-junio/20200629191354176682.html

(33) Véase Gómez, R. (2019). La negociación colectiva en las reformas de 2018 y 2019. Temas Laborales, 147, $151-174$. 
sólo que las limitaciones de la libre circulación hayan tenido un impacto indirecto en la práctica, sino que, por añadidura, han primado las urgencias derivadas de la necesidad de que las empresas, organizaciones empresariales e incluso de las propias representaciones sindicales hayan debido concentrar todos sus esfuerzos en el modo de actuar frente a un escenario económico, empresarial y laboral que se ha alterado sustancialmente. Tal lógica preferencia por la reacción frente al modo de actuar frente al Covid-19, ha provocado con naturalidad un impacto automático sobre los procesos ordinarios de negociación colectiva. Por último, vertiente probablemente más decisiva aún, el profundo cambio del escenario económico, empresarial y del empleo a resultas de la crisis económica derivada de la paralización de la actividad económica, con un panorama de enorme incertidumbre exigen un cambio en el diagnóstico de la situación y, por ende, un cambio en las posiciones de las partes respecto de los que pueden reclamar o aceptar en una mesa de negociación colectiva.

En definitiva, resulta más que comprensible y razonable que se haya abierto un paréntesis $y$, con el mismo, un temporal bloqueo de la negociación colectiva, Hasta tanto no se supere mínimamente los elementos de incertidumbre respecto del inmediato futuro, incluso a la espera de un posible Acuerdo interconfederal de negociación colectiva de gestión futura de las relaciones laborales. Posiblemente ese hipotético acuerdo interconfederal, de alcanzarse, será decisivo a los efectos de la reconstrucción económica del país, al extremo que constituirá una pieza clave de las medidas de reconstrucción, en su caso a consensuar en el ámbito político general, que, por tanto, igualmente volverán a atribuir una función decisiva a la negociación colectiva dentro de nuestro sistema de relaciones laborales.

De otro lado, destacar igualmente cómo la participación de los trabajadores en la empresa constituye un elemento central de nuestro sistema de relaciones laborales, con atribución de muy importantes competencias de información y consulta a los representantes de los trabajadores en la empresa, especialmente ante escenarios en los que las empresas se ven abocadas a adoptar medidas de reestructuración empresarial. Pues bien, también desde esa perspectiva se aprecia una marginalidad de los procesos de consultas con la representación de los trabajadores, respondiendo a ello una vez más el tipo de medidas laborales adoptadas en este contexto del estado de alarma. Una vez más las razones de urgencia y el superior protagonismo atribuido a la autoridad laboral en este contexto, como efecto derivado, ha provocado un venir a menos de la intervención de los representantes de los trabajadores en esta primera fase de respuesta a la paralización de la actividad productiva.

Finalmente, el hecho de que el establecimiento del trabajo a distancia como fórmula prioritaria en la medida en que sea posible, se ha introducido imponiendo un directo doble deber empresarial y de los trabajadores, que remite a una reorganización implementada por la vía estrictamente individual y, por tanto, sin contemplar nuestra legislación previa ni la de emergencia fórmula de intervención por parte de los representantes de los trabajadores. A estos efectos, la ausencia de protagonismo de los representantes de los trabajadores en los procesos de adaptación hacia trabajos a distancia, particularmente a fórmulas de trabajo semipresencial, constituye una gran carencia de nuestro ordenamiento jurídico, elemento que debería se reconsiderado para la fase de la post-emergencia.

Por contraste con esa marginalidad de la intervención en clave de información y consulta a los representantes en la fase dura de la emergencia, y a pesar de todo lo anterior, es previsible que la siguiente fase, en la que se va produciendo la paulatina vuelta a la actividad económica y, con ella, una progresiva reincorporación al trabajo de quienes se encontraban con su relación laboral en suspenso, está propiciando ya una recuperación del protagonismo que le debe corresponder a los representantes de los trabajadores. En esta fase sucesiva, por varias razones, es lógico pensar que se produzca una intensificación de los procesos de información y consulta a los representantes de los trabajadores.

\section{Resumen conclusivo}

La declaración del estado de alarma por parte del Gobierno español en el marco de la pandemia ha provocado un impacto muy intenso sobre el empleo, que ha determinado la adopción de medidas de gran calado en el ámbito laboral y de la Seguridad Social. Especialmente las medidas laborales han ido dirigidas a evitar la destrucción del empleo, por medio del favorecimiento del trabajo a distancia y de la suspensión de los contratos de trabajo, seguida tras el levantamiento del estado de alarma de medidas de fomento de la reincorporación de los trabajadores a sus puestos de trabajo. Desde el punto de vista social, las medidas han ido dirigidas 
esencialmente a establecer un amplio sistema de prestaciones económicas para atender la pérdida de rentas salariales por parte de quienes se han vistos impedidos de trabajar, así como hacer frente a las situaciones de pobreza extrema.

En el terreno de la garantía de los derechos fundamentales, la declaración del estado de alarma sólo podía provocar una limitación del derecho de circulación de los trabajadores, sin posible impacto sobre los derechos constitucionales de los trabajadores. Sin embargo, como efecto reflejo se han producido importantes limitaciones en el ejercicio de tales derechos, como son los relativos al derecho de manifestación pública, como igualmente en el campo de la efectividad de nuevos derechos como son los relativos a la protección de datos personales.

Para la valoración de la significación de las medidas adoptadas resulta de particular importancia en detectar hasta que puntos las mismas han resultado de real aplicación y cumplimiento (efectividad), así como que con su cumplimiento se ha logrado sus objetivos y fines (eficacia), dentro de un equilibrio razonable entre efectos y costes (eficiencia). En una primera aproximación puede afirmarse que la efectividad de las medidas a corto plazo ha sido muy elevado, manifestada sobre todo en que por primera vez en España ante una fuerte crisis de empleo se ha logrado canalizar las dificultades de empleo por vía de las suspensiones de los contratos en lugar de a través de los despidos, así como en el terreno social porque se ha contenido la caída del consumo de la población de los bienes de primera necesidad por el fuerte incremento del gasto social en prestaciones económicas de Seguridad Social. No obstante, el panorama, junto a sus luces, también ha tenido sus sombras, centradas especialmente en una fuerte destrucción de empleo de quienes se encontraban contratados temporalmente, sin dejar de señalar que la valoración definitiva debe esperar a que transcurra todavía un tiempo y se pueda comprobar, de un lado, si el grueso de los trabajadores que han visto suspendidos sus contratos logran reincorporarse efectivamente a sus anteriores empleos, y, de otro lado, cuál es el impacto real de la implantación del Ingreso Mínimo Vital en reducir las situaciones de extrema pobreza y, en particular, de la pobreza infantil.

Las medidas han tenido un carácter esencialmente coyuntural, concebidas para durar tan sólo el tiempo imprescindible en el que se prolongue el estado de crisis sanitaria. Sin embargo, las mismas han dejado su poso, de modo que han tenido un efecto de puesta en marcha de reformas legislativas de alcance temporal, para introducir regulaciones permanentes en el tiempo. Desde el punto de vista laboral, destaca el proyecto del Gobierno de aprobar una regulación completa del trabajo a distancia. Desde el punto de vista social sobresale la medida ya adoptada de introducción dentro del sistema de Seguridad Social de una nueva prestación, denominada Ingreso Mínimo Vital, que pretende garantizar una renta de subsistencia para todos aquellos que demuestren un estado de necesidad objetiva no cubierto por los mecanismos hasta ahora existentes de protección social.

Desde el punto de vista de las Fuentes del Derecho contempladas en el ordenamiento jurídico laboral, en base a las razones de urgencia concurrentes ante la crisis sanitaria, la totalidad de las medidas, tanto laborales como sociales, han sido aprobadas por medio del instrumento del Real Decreto-Ley. Ello supone aprobación inmediata por el poder ejecutivo, Consejo de Ministros, con una intervención muy limitada por parte del Congreso de los Diputados, como depositario constitucional del poder legislativa, que se limita a ratificarlo o derogarlo en una inmediata votación de conjunto. Aunque se ha acudido sucesivamente a la técnica habitual de convertir el Real Decreto-Ley en proyecto de ley de tramitación ordinaria, que otorga mayor protagonismo en la práctica al Parlamento, en la práctica ello va a tener un simbolismo puramente político, porque en la práctica no va a existir tiempo material de actuación del Parlamento, ya que el contenido de las medidas va a agotarse en el tiempo de vigencia previsto antes de que se debate en sede parlamentaria.

Otro de los elementos más significativos ha sido el recurrente uso que se ha hecho de decisiones de rango reglamentario inferior, como es el acudir de manera muy recurrente a la aprobación de Órdenes Ministeriales. Incluso a veces se trata de decisiones que presentan dudas de su carácter reglamentario, en la medida en que se dictan por medio de simples Resoluciones de órganos administrativos inferiores al propio Ministro, algo poco admisible desde el punto de vista constitucional.

La de redacción de las normas aprobadas para introducir las medidas laborales y sociales de manera más que reiterada se encuentran rodeadas de imprecisiones técnicas, incluso cabe aventurar que, en algunos casos, conscientemente introducidas por el legislador y no atribuibles a la mera celeridad con la que se ha producido la 
elaboración de estas medidas legislativas. Ello ha provocado una inseguridad jurídica que, a su vez, da lugar en unas ocasiones a un incremento de la litigiosidad judicial y en otros casos a una intensificación del margen de actuación de la Administración laboral en su labor de ejecución de la legislación laboral $\mathrm{y}$, en todo caso, coloca a los destinatarios de esas normas en una posición de notable dificultad a la hora de decidir cómo adaptan sus comportamientos a los efectos de un correcto cumplimiento de las medidas legislativas adoptadas. Para superar estos problemas en ocasiones la Administración ha aprobado Guías orientativas, de protocolos de actuación, o bien de resoluciones de respuestas a consultas de particulares, que se sitúan en el territorio típico de los instrumentos de "soft law", pero que han tenido una enorme relevancia práctica. La actuación judicial más relevante durante la pandemia se ha producido a resultas de reclamaciones presentadas frente a las Administraciones Públicas, especialmente frente a las competentes en materia de gestión de la asistencia sanitaria pública, en orden a las medidas especiales que se deberían adoptar para proteger frente al posible contagio del virus por parte del personal sanitario. En muchas ocasiones ha venido precedida por denuncias ante la Inspección de Trabajo, que ha desplegado una labor encomiable de asesoramiento y vigilancia de la salud en momentos tan delicados y complejos, pero que igualmente en paralelo ha provocado la existencia de importantes resoluciones judiciales en esta materia.

La urgencia en la intensa actividad desplegada por el Gobierno en la primera fase de implementación del estado de alarma provocó que no funcionasen los mecanismos habituales de concertación social, ante decisiones de tanto calado en el ámbito tanto laboral como de Seguridad Social. No obstante, las propuestas conjuntamente formuladas por las organizaciones sindicales y empresariales tuvieron su impacto, al tiempo que fue decisivo el apoyo público que tales asociaciones otorgaron a las medidas gubernamentales. Conforme la situación se "normalizó" desde el punto de vista institucional, se han retomado los procesos de diálogo social, alcanzándose dos importantes acuerdos a nivel general respecto de las medidas a adoptar para el proceso de recuperación de la actividad económica y del empleo, una vez concluida la fase dura de actuación frente a la expansión del virus. Igualmente se ha recuperado el proceso de diálogo social respecto de las medidas estructurales de reforma laboral, como han sido las relativas a la nueva regulación del teletrabajo.

Igualmente, dentro del ámbito del desarrollo de la autonomía colectiva, la urgencia con la que se han tenido que adoptar todas las medidas de referencia ha provocado que también haya pasado a un muy segundo plano la intervención tanto de la negociación colectiva como del ejercicio de las facultades de consulta a los representantes de los trabajadores. 